\title{
Evaluating the effects of pain and disorders of the knee joint on knee extension strength and daily life activities in the female elderly ${ }^{*}$
}

\author{
Hiroki Sugiura $^{1 \#}$, Shinichi Demura ${ }^{1}$, Kenji Takahashi $^{2}$ \\ ${ }^{1}$ Graduate School of Natural Science and Technology, Kanazawa University, Ishikawa, Japan; \\ \#Corresponding Author: sghiro92@ed.kanazawa-u.ac.jp \\ ${ }^{2}$ Faculty of Community Health Care, Teikyo Heisei University, Chiba, Japan
}

Received 10 August 2013; revised 2 September 2013; accepted 27 September 2013

Copyright (C) 2013 Hiroki Sugiura et al. This is an open access article distributed under the Creative Commons Attribution License, which permits unrestricted use, distribution, and reproduction in any medium, provided the original work is properly cited.

\begin{abstract}
This study aimed at examining the differences in leg strength and activities of daily living (ADL) ability among groups with various knee problems. The subjects consisted of $\mathbf{3 2 8}$ elderly females who were classified into three groups: those without knee pain or a knee disorder, those with knee pain, and those with a knee disorder. The subjects took a knee extension strength test and an ADL survey. Knee extension strength and ADL scores (total score and each domain score of the motions of locomotion, posture change, stability, and manipulation) were selected as the evaluation parameters. The knee extension strength, total ADL score and each domain score of the motions of locomotion, posture change, and stability ranged from low to high in the following order: the group with a knee disorder, the group with knee pain, and the group without pain or a knee disorder. Moreover, manipulation scores were significantly inferior in the group with a knee disorder compared with the other two groups. In conclusion, the female elderly with knee pain or a knee disorder have inferior knee extension strength and ADL with respect to the motions of locomotion, posture change and stability. In addition, with regard to knee extension strength with respect to the above three motions, the elderly with a knee disorder have inferior scores when compared with the elderly who have only knee pain; thus, they find it difficult to perform activities involving the knee joints.
\end{abstract}

\footnotetext{
"Research funds were not provided by any institution.
}

Keywords: Knee Joint Pain; Knee Joint Disorder; Knee Extension Strength; ADL; Female Elderly

\section{INTRODUCTION}

At an advanced age, leg strength, balance and leg joint functions have a tendency to decrease. As a result, the ability to perform activities of daily living (ADL) is lowered and a decrease in this ability is also apparent [1,2]. In addition, the decrease greatly affects the occurrence of falls $[3,4]$ and quality of life (QOL) [5]. Therefore, it is necessary for the elderly to prevent a decrease in physical functions in order to achieve and maintain an independent daily life.

Among all the leg joints, knee joints have the greatest load capacity and are important for efficient performance of ADL [6]. Recent observations revealed an increase in the number of elderly suffering from knee disorders [7]; in addition, Tennant et al. [8] reported that $8 \%$ of the elderly have knee disorders. According to Ikushima et al. [9], the main cause of decrease in the ability to perform ADL in the elderly is a decrease in leg strength and disorders in the knee joint. In general, leg strength does decrease with age [10-12]; however, in case of the elderly with knee joint disorders, active mass decreases markedly due to the disorder which subsequently causes a rapid decrease in leg strength [13]. In addition, the decrease in leg strength at an advanced age causes a decrease in ability to perform ADL [14-16]. Hence, it is assumed that the elderly suffering from a knee disorder have inferior ability to perform ADL.

On the other hand, despite the absence of a severe knee disorder, many elderly experience subjective knee pain $[7,17,18]$. They can be considered as an auxiliary group of the elderly with knee disorders. Mc Alindon et al. [19], Reilly et al. [20], and Urwin et al. [21] reported 
that about $20 \%$ of the elderly suffered from knee pain. Sugiura and Demura [22] reported that knee extension strength and the ability to perform ADL were inferior in the group with knee pain when compared with the group without knee pain. Therefore, it is assumed that the elderly with knee pain have inferior ability to perform ADL as compared to the elderly suffering from a knee disorder.

The ADL consists of four domains: locomotion, manipulation, stability, and posture change $[23,24]$; the ability to perform these motions is important for the elderly to maintain an independent daily life. Manipulation motions mainly use the upper limbs, but the other three motions are significantly affected by movements of the knee joint. Hence, it is assumed that those who suffer from knee pain and/or disorders are less efficient in performing these three motions. In addition, it is assumed that subjects with a specific knee disorder are less efficient in performing the above three motions compared with the elderly who suffer from only knee pain. The latter group is considered to be the reserve group of those with a knee disorder.

It has been reported that the prevalence of knee pain and knee disorders is high in the female elderly $[7,25]$. This study aimed to examine the differences in knee extension strength and ADL among the female elderly who were divided into the following three groups: those without knee pain or a knee disorder, those with knee pain, and those with a knee disorder.

\section{METHOD}

\subsection{Subjects}

The subjects consisted of 328 elderly female subjects (60 - 94 years old; mean age 76.1 years; SD = 6.2) participating in health classes or social educational activities hosted by municipal governments. These women were classified into the following three groups: 168 females without knee pain or disorder (G1, knee no-pain and disorder group), 116 females with subjective knee pain (G2, one knee pain group, $n=75$; G3, both knees pain group, $n=41$ ), and 44 females with a knee disorder (G4, one knee disorder group, $n=21$; G5, both knees disorder group, $n=23)$. Forty females in the knee pain group and 11 females in the knee disorder group had right knee pain. The knee pain and disorders were judged by the Japanese edition of knee function scale based on the Western Ontario and McMaster Universities Osteoarthritis Index (WOMAC) [26] prepared by Hashimoto et al. [27]; the cut-off point was set at 210 points [25]. The elderly with a knee disorder could perform limited activities and regularly visited a hospital for treatment of their knee disorders; however, they could independently perform ADL. In general, we observed that the elderly with a knee disorder could not perform ADL efficiently. If the
ADL levels achieved by the subjects with knee disorders in this study were lower than those achieved by the general elderly population, the levels achieved by elderly subjects with knee disorders should be even lower. Table $\mathbf{1}$ lists the basic statistics of age, height, and body weight for each group. Before the study was conducted, the purpose and procedure of this study were explained to all of the subjects in detail and informed consent was obtained. The present experimental protocol was approved by the Ethics Committee on Human Experimentation of Faculty of Human Science, Kanazawa University (Ref. No. 2012-12).

\subsection{Leg Strength}

To evaluate the leg strength, we selected the measurements of knee extension strength as it is severely affected by knee pain or knee disorder [22,28,29]. During the measurement of isometric knee extension strength, the subjects were seated upright in a rigid chair with knees flexed at a $90^{\circ}$ angle. Their lower legs were strapped by a pad just above the ankle and attached with a backward rigid bar to a tension meter (T.K.K.1269f; Takei Scientific Instruments Co. Ltd., Japan). In addition, the subjects folded their arms across their chest. An examiner held the pad fixed in its place and asked the subjects to extend their knee as far as possible and to hold the position for $3 \mathrm{~s}$. Leg strength was measured twice for each of the legs and a mean of two trials was used as a parameter for each leg. Furthermore, for knee no-pain and disorder group, both knees pain group, and both knees disorder group, a mean of the above values (for right and left legs) was used as a parameter.

\subsection{ADL}

The ADL survey developed by the Ministry of Education, Culture, Sports, Science and Technology of Japan was used to evaluate activities of daily living (Table 2). This survey was created to assess the physical function level at which the elderly would be able to safely participate in a physical fitness test. This survey method consists of four domains: locomotion (walking, running, jumping across a ditch, ascending and descending stairs, convey), posture change (sitting up, standing up from the floor), stability (standing on one foot with eyes open, standing in a bus or train, dressing while standing) and manipulation (buttoning a shirt, taking a Japanese mattress in and out of the closet), thereby assessing the degree of achievement of ADL based on these 12 activities, which are essential for an independent living [23,24]. Each item had 3 different levels of difficulty. The subjects answered any one of three responses for each question. The total score in each domain and the total score with respect to these 12 activities were calculated. In addition, the 
Table 1. The basic statistics and test results of age, height and body weight among groups.

\begin{tabular}{|c|c|c|c|c|c|c|c|c|c|c|c|c|c|c|c|c|c|c|c|c|c|c|c|c|}
\hline & \multicolumn{4}{|c|}{$\begin{array}{c}\text { Knee no-pain and } \\
\text { disorder } \\
(\mathrm{G} 1: n=168)\end{array}$} & \multicolumn{4}{|c|}{$\begin{array}{l}\text { One knee pain } \\
(\mathrm{G} 2: n=75)\end{array}$} & \multicolumn{4}{|c|}{$\begin{array}{l}\text { Both knees pain } \\
\quad \text { (G3: } n=41 \text { ) }\end{array}$} & \multicolumn{4}{|c|}{$\begin{array}{l}\text { One knee disorder } \\
\quad(\mathrm{G} 4: n=21)\end{array}$} & \multicolumn{4}{|c|}{$\begin{array}{l}\text { Both knees disorder } \\
\quad(\mathrm{G} 5: n=23)\end{array}$} & \multicolumn{3}{|c|}{ ANOVA } & \multirow[t]{2}{*}{$\begin{array}{l}\text { Scheff's } \\
\text { Post-hoc }\end{array}$} \\
\hline & M & $\mathrm{SD}$ & MAX & MIN & M & SD & MAX & MIN & $\mathrm{M}$ & SD & MAX & MIN & $\mathrm{M}$ & SD & MAX & MIN & $\mathrm{M}$ & SD & MAX & MIN & $F$ & $p$ & $\eta^{2}$ & \\
\hline $\begin{array}{l}\text { Age } \\
\text { (yr) }\end{array}$ & 75.4 & 6.7 & 88 & 62 & 76.8 & 6.0 & 94 & 60 & 76.4 & 5.2 & 86 & 60 & 76.7 & 5.1 & 87 & 68 & 77.5 & 5.7 & 85 & 60 & 1.10 & 0.36 & 0.01 & - \\
\hline $\begin{array}{l}\text { Height } \\
(\mathrm{cm})\end{array}$ & 147.8 & 6.2 & 164.5 & 132.5 & 147.2 & 6.2 & 161.4 & 4132.5 & 5147.7 & 5.7 & 160.0 & 138.4 & 149.1 & 5.0 & 156.0 & 138.0 & 146.7 & 75.9 & 159.4 & 140.0 & 0.47 & 0.76 & 0.01 & - \\
\hline $\begin{array}{l}\text { Weight } \\
(\mathrm{kg})\end{array}$ & 48.40 & 7.6 & 69.6 & 32.1 & 49.321 & 12.4 & 70.9 & 32.5 & 53.76 & 7.4 & 69.1 & 40.8 & 54.69 & 6.9 & 71.0 & 39.0 & 53.42 & 6.6 & 68.8 & 41.7 & $3.08^{*}$ & 0.02 & $0.04^{\mathrm{C}}$ & $\begin{array}{c}\mathrm{G} 1<(\mathrm{G} 4 \\
\quad+\mathrm{G} 5)\end{array}$ \\
\hline
\end{tabular}

Table 2. ADL test.

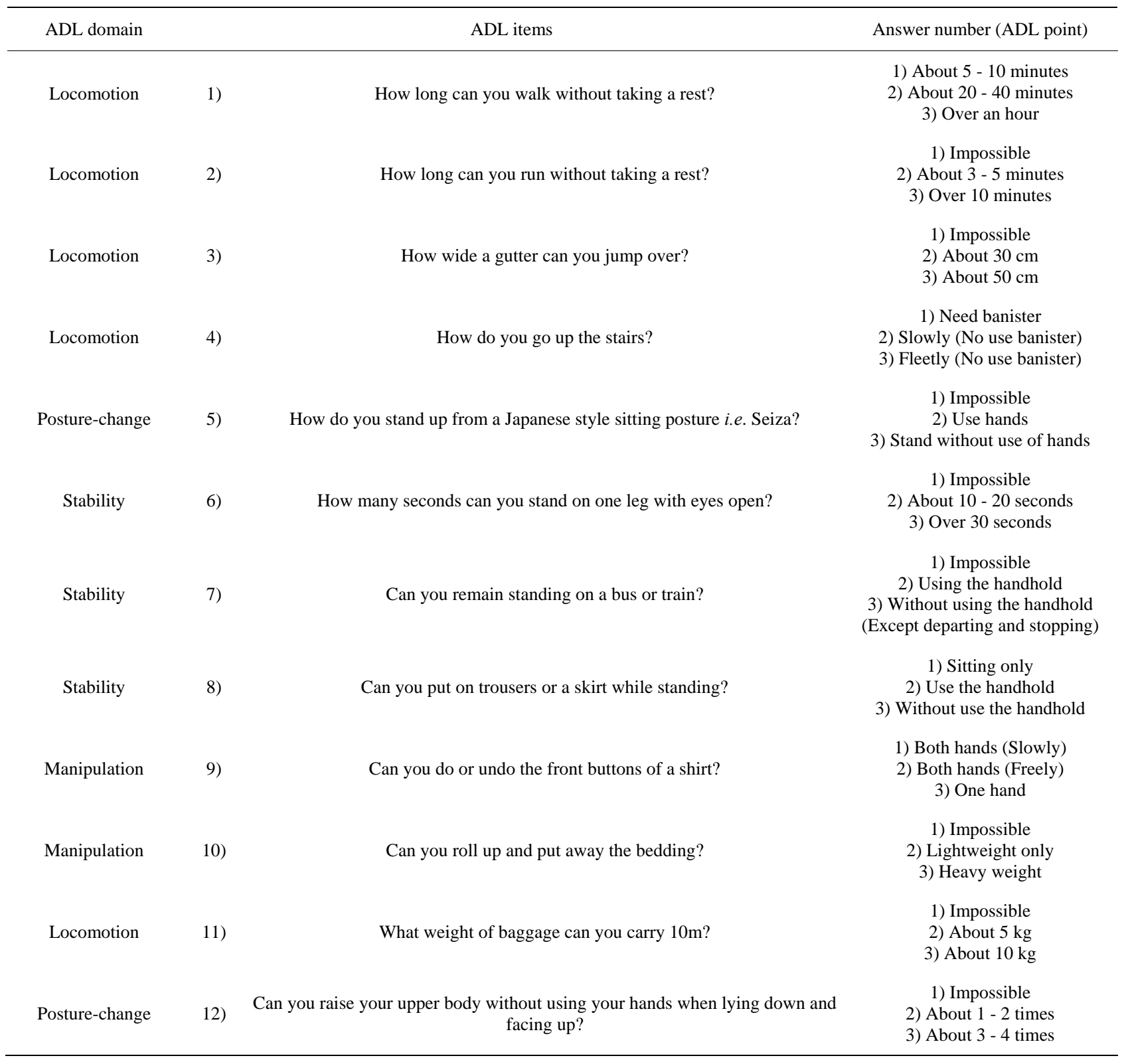


elderly with higher ADL scores were judged to have superior ability to perform ADL.

\subsection{Statistical Analysis}

Mean differences of knee extension strength and each ADL score were examined using the analysis of covariance (ANCOVA) with body weight as a covariate. A Scheffe's test was used as a linear comparison test if a significant difference was observed among the means. The laterality of knee extension strength in G2 and G4 was examined by paired t-test. A significance level in this study was set at $p<0.05$.

\section{RESULTS}

Table 1 lists the basic statistics of age, height and body weight in the knee no-pain and disorder (G1), one knee pain (G2), both knees pain (G3), one knee disorder (G4), and both knees disorder (G5) groups, and the test results when their mean values were compared. The results of the one-way analysis of variance (ANOVA) showed a significant difference with respect to body weight only. Subjects in knee disorder group (G4 + G5) were significantly heavier than the no knee pain or disorder group (G1). Additionally, the body weight between G2 and G3, as well as between G4 and G5 showed an insignificant difference.

Table 3 shows the basic statistics and test results of knee extension strength in the above five groups. For G1, G3, and G5, we used a mean of right and left values; for G2, we used a value of the leg with pain; and, for G4, we used the value of the leg with disorder (see leg strength section in the method). Results of ANCOVA showed a significant difference. A linear comparison test revealed that the knee extension strength was significantly lower in the following order: the knee disorder group, the knee pain group, and the knee no-pain and disorder group. Additionally, the knee extension strength between G2 and G3, and between G4 and G5 showed an insignificant difference. Knee extension strength between the disordered leg and the normal leg in the one knee disorder group, and between the leg with pain and the normal leg in the one knee pain group revealed a significant difference; moreover, the disordered leg and the leg with pain results were inferior to the other leg results (Table 4).

Table 5 shows basic statistics and test results of ADL total score and each domain score in the above five groups. The result of ANCOVA showed a significant difference between the means. A linear comparison test revealed that the ADL total score and each domain score of locomotion, posture change and stability motions were significantly lower in the following order: the knee disorder group, the knee pain group, and the knee no-pain and disorder group. The manipulation scores were significantly inferior in the group with a knee disorder when compared to the other two groups. Overall, ADL total scores and each domain score with respect to locomotion, posture change and stability motions were significantly lower in the following order: the one knee disorder and the both knees disorder groups; the one knee pain and the both knees pain group; and finally, the knee no-pain and disorder group. However, no significant differences were observed between G2 and G3, and between G4 and G5.

\section{DISCUSSION}

The knee disorder group was heavier than the knee no-pain and disorder group. The knee joints play an important role in supporting body weight [9]. While standing on one leg or walking, the load imposed on the weight-bearing knee joint is double that of normal [30]. Oliveria et al. [31] and Yoshimura et al. [32] reported that knee disorders often occur due to large burden on the knee joints, imposed by heavy body weight. It was speculated that the subjects with a knee disorder either decreased their physical active mass as they were limited by their knee disorders, or reduced the burden to the knee joints thereby causing their body weight to increase. In any of these cases, we inferred that the elderly with a knee disorder are heavier than the elderly without knee pain and/or a knee disorder; furthermore, the elderly with a knee disorder do not have a large portion of the body weight imposed on the knee joints.

In this study, knee extension strength was measured in the seated position. Therefore, while measuring the leg strength, it was considered that the burden of body weight did not significantly affect the knee joints. The knee extension strength results were observed lowering in the following order: the knee disorder group, the knee pain group, and the knee no-pain and disorder group. We inferred that the leg strength in elderly with knee disorder was inferior to the elderly with knee pain, and leg strength of the above groups was inferior to the elderly without knee pain or disorder. Moreover, with regard to leg strength measurements, the knee pain and knee disorder groups may not be able to exert sufficient leg strength to counter the body weight burden, similar to that during daily activities. Furthermore, with regard to leg strength, we observed the following results as well:

1) The disordered leg was inferior to the leg without disorder in the one knee disorder group.

2) The leg with pain was inferior to the no-pain leg in the one knee pain group.

The results of the one knee pain group were similar to Sugiura and Demura's results [22,29]. Additionally, strength exertion of the leg with disorder may be limited in the one knee disorder group.

The present ADL survey consists of 4 domains of locomotion, manipulation, stability and posture change 
Table 3. The basic statistics and test results of knee extension strength among groups.

\begin{tabular}{|c|c|c|c|c|c|c|c|c|c|c|c|c|c|c|c|c|c|c|c|c|c|c|}
\hline & \multicolumn{3}{|c|}{$\begin{array}{c}\text { Knee no-pain and } \\
\text { disorder } \\
(\text { G1: } n=168)\end{array}$} & \multicolumn{4}{|c|}{$\begin{array}{c}\text { One knee pain } \\
\text { [Pain leg] } \\
(\mathrm{G} 2: n=75)\end{array}$} & \multicolumn{4}{|c|}{$\begin{array}{l}\text { Both knees pain } \\
\quad(\mathrm{G} 3: n=41)\end{array}$} & \multicolumn{4}{|c|}{$\begin{array}{l}\text { One knee disorder } \\
\text { [Disorder leg] } \\
\text { (G4: } n=21)\end{array}$} & \multicolumn{4}{|c|}{$\begin{array}{l}\text { Both knees disorder } \\
\quad \text { (G5: } n=23)\end{array}$} & \multicolumn{2}{|c|}{ ANCOVA } & \multirow[t]{2}{*}{$\begin{array}{l}\text { Scheff's } \\
\text { post-hoc }\end{array}$} \\
\hline & $\mathrm{M}$ & SD & MAX MIN & M & SD & MAX & MIN & M & $\mathrm{SD}$ & MAX & MIN & $\mathrm{M}$ & $\mathrm{SD}$ & MAX & MIN & M & $\mathrm{SD}$ & MAX & MIN & $F$ & $\eta^{2}$ & \\
\hline $\begin{array}{l}\text { Knee } \\
\text { extension } \\
\text { strength } \\
\text { (kg) }\end{array}$ & 7.42 & 2.17 & 15.413 .27 & 6.16 & 1.73 & 9.53 & 1.98 & 6.19 & 1.69 & 9.43 & 5.87 & 5.20 & 1.66 & 9.15 & 1.69 & 5.36 & 1.44 & 9.07 & 1.80 & $18.6^{*}$ & 0.0000 .06 & $\begin{array}{c}(\mathrm{G} 4+\mathrm{G} 5) \\
<(\mathrm{G} 2+ \\
\mathrm{G} 3)<\mathrm{G} 1\end{array}$ \\
\hline
\end{tabular}

Note: ${ }^{*} p<0.05$.

Table 4. Laterality of knee extension strength in the one knee pain and one knee disorder groups.

\begin{tabular}{|c|c|c|c|c|c|c|c|c|c|c|c|}
\hline & \multicolumn{4}{|c|}{ Pain or disorder leg } & \multicolumn{4}{|c|}{ Healthy leg } & \multicolumn{3}{|c|}{ t-test } \\
\hline & M & $\mathrm{SD}$ & MAX & MIN & M & $\mathrm{SD}$ & MAX & MIN & $t$ & $p$ & ES \\
\hline One knee pain (G2: $n=75$ ) & 6.16 & 1.73 & 9.53 & 1.98 & 6.61 & 2.01 & 12.52 & 2.01 & $3.02^{*}$ & 0.003 & 0.22 \\
\hline One knee disorder (G4: $n=21$ ) & 5.20 & 1.66 & 9.15 & 1.69 & 5.77 & 1.69 & 9.54 & 1.95 & $2.02^{*}$ & 0.03 & 0.34 \\
\hline
\end{tabular}

Note: ${ }^{*} p<0.05$.

Table 5. The basic statistics and test results of ADL score and each domain score among groups.

\begin{tabular}{|c|c|c|c|c|c|c|c|c|c|c|c|c|c|c|c|c|c|c|c|c|c|c|c|c|}
\hline & \multicolumn{4}{|c|}{$\begin{array}{c}\text { Knee no-pain and } \\
\text { disorder } \\
\text { (G1: } n=168)\end{array}$} & \multicolumn{4}{|c|}{$\begin{array}{l}\text { One knee pain } \\
\text { (G2: } n=75)\end{array}$} & \multicolumn{4}{|c|}{$\begin{array}{l}\text { Both knees pain } \\
\quad \text { (G3: } n=41)\end{array}$} & \multicolumn{4}{|c|}{$\begin{array}{l}\text { One knee disorder } \\
\quad(\mathrm{G} 4: n=21)\end{array}$} & \multicolumn{4}{|c|}{$\begin{array}{l}\text { Both knees disorder } \\
\quad(\mathrm{G} 5: n=23)\end{array}$} & \multicolumn{3}{|c|}{ ANCOVA } & \multirow[t]{2}{*}{$\begin{array}{l}\text { Scheff's } \\
\text { post-hoc }\end{array}$} \\
\hline & M & SD & MAX & MIN & $\mathrm{M}$ & SD & MAX & MIN & $\mathrm{M}$ & SD & MAX & MIN & $\mathrm{M}$ & SD I & MAX & MIN & $M$ & SD & MAX & MIN & $F$ & $p$ & $\eta^{2}$ & \\
\hline $\begin{array}{l}\text { ADL total } \\
\text { score }\end{array}$ & 27.0 & 4.6 & 36 & 13 & 24.5 & 4.7 & 34 & 15 & 23.9 & 4.7 & 32 & 14 & 20.1 & 4.7 & 29 & 11 & 18.3 & 4.0 & 28 & 11 & $22.3^{*}$ & 0.000 & 0.24 & $\begin{array}{c}(\mathrm{G} 4+\mathrm{G} 5) \\
<(\mathrm{G} 2+ \\
\mathrm{G} 3)<\mathrm{G} 1\end{array}$ \\
\hline Locomotion & 10.7 & 2.4 & 15 & 4 & 9.7 & 2.4 & 15 & 4 & 9.2 & 2.4 & 15 & 5 & 7.1 & 2.9 & 13 & 2 & 7.0 & 2.0 & 11 & 3 & $15.6^{\ddagger}$ & 0.000 & 0.18 & $\begin{array}{c}(\mathrm{G} 4+\mathrm{G} 5) \\
<(\mathrm{G} 2+ \\
\mathrm{G} 3)<\mathrm{G} 1\end{array}$ \\
\hline $\begin{array}{l}\text { Posture } \\
\text { change }\end{array}$ & 4.4 & 1.1 & 6 & 2 & 3.7 & 1.1 & 6 & 1 & 3.7 & 1.1 & 6 & 2 & 2.8 & 1.0 & 4 & 0 & 2.8 & 0.8 & 5 & 2 & $19.9^{\ddagger}$ & 0.000 & 0.22 & $\begin{array}{c}(\mathrm{G} 4+\mathrm{G} 5) \\
<(\mathrm{G} 2+ \\
\mathrm{G} 3)<\mathrm{G} 1\end{array}$ \\
\hline Stability & 7.2 & 1.3 & 9 & 3 & 6.6 & 1.3 & 9 & 3 & 6.6 & 1.3 & 9 & 4 & 5.5 & 1.8 & 9 & 1 & 5.0 & 1.4 & 8 & 3 & $15.0^{\ddagger}$ & 0.000 & 0.17 & $\begin{array}{c}(\mathrm{G} 4+\mathrm{G} 5) \\
<(\mathrm{G} 2+ \\
\mathrm{G} 3)<\mathrm{G} 1\end{array}$ \\
\hline Manipulation & 4.7 & 1.0 & 6 & 2 & 4.5 & 1.0 & 6 & 1 & 4.4 & 1.0 & 6 & 2 & 4.0 & 1.0 & 5 & 1 & 3.5 & 1.0 & 6 & 2 & $6.34^{\ddagger}$ & 0.000 & 0.08 & $\begin{array}{l}(\mathrm{G} 4+\mathrm{G} 5) \\
<\mathrm{G} 1,(\mathrm{G} 2 \\
\quad+\mathrm{G} 3)\end{array}$ \\
\hline
\end{tabular}

Note: ${ }^{*} p<0.05,{ }^{\ddagger} p<0.05 / 4=0.0125$.

$[23,24]$, which systematically evaluates the achievement degree of various activities of daily living of the elderly. The ADL score between the groups of one knee and both knees pain, as well as between the groups of one knee and both knees disorder revealed an insignificant difference. Although it was hypothesized that with regard to ADL, the both knees pain/disorder group was inferior to the one knee pain/disorder group, this hypothesis could not be confirmed. Sugiura and Demura [22,29] reported that there was no significant difference in the ADL scores between the pain in one knee group to those with pain in both knees. Several movements of daily life such as standing up, walking and ascending and descending stairs require equal use of both the legs. Because the elderly in this study could walk independently, they could have achieved daily life activities despite the enduring pain. From these results, it was inferred that the elderly with pain or a disorder in one knee face difficulties in performing ADL and were able to achieve the same QOL as the elderly with pain or a disorder in both knees.

Based on the above results, for the purpose of analysis in this study, both groups with one knee pain and both knees pain were pooled as the knee pain group and both groups with one knee disorder and both knees disorder 
were pooled as the knee disorder group, respectively. Consequently, the observed lowering of the total ADL score was in the following order: the group with a knee disorder; the group with knee pain; and eventually, the group without pain or a knee disorder. Furthermore, a strong relationship has been reported between knee extension strength and ADL [14-16].

It is essential to exert leg strength in order to perform activities of daily living; however, if leg strength is inferior, especially at an older age, it may strongly affect the activities of daily living. In addition, the total ADL score along with knee extension strength revealed a significant difference between the elderly with knee pain and those with a knee disorder. As mentioned above, because our measurements were performed at a seated position (see subjects section in the method), the burden of body weight imposed a minimum of stress on the knee joint. Nevertheless, knee extension strength was decreased in the elderly with knee pain or a knee disorder. Because most daily life activities are performed in the standing position, the burden of body weight is imposed upon the knee joints; thus, it was inferred that ADL in the elderly with a specific knee disorder was inferior to elderly with knee pain, and ADL in the elderly with knee pain was inferior to the elderly without knee pain.

Each domain score of locomotion, posture change, and stability motions except for manipulation motions gave the same results as the ADL total score. Locomotion, posture change, and stability motions always involve the use of legs to some degree. From these results, it was inferred that if the subject has a problem involving the knee joints, the above motions are limited. On the contrary, with regard to motions of manipulation, it was clarified that the performance of the group with a knee disorder was inferior to the no-pain and disorder group as well as the knee pain group. Spector et al. [33] and Kim et al. [34] reported that there is little decrease in the dexterity and skill of hands or fingers with age. It is possible that the knee disorder not only causes limitation of physical active mass in locomotion, posture change and stability motions, but also a reduction in the degree of use of the upper limbs. Therefore, early care for knee disorders is essential.

In this study, subjects with or without knee pain and with or without disorders were evaluated on the basis of their subjective judgment because we targeted many elderly individuals. In addition, the elderly with knee pain or knee disorders were judged using Japanese edition of knee function scale (see the method section). Their diagnoses might have been different when the doctors assessed their radiographs. Thus, it might be necessary to also add the judgment based on the doctor's diagnosis in addition to evaluating the degree of achievement of basic life activities including manipulation motions.

\section{CONCLUSION}

In conclusion, with regard to knee extension strength and ADL scores of locomotion, posture change and stability motions, elderly females with knee pain or disorder are inferior to the elderly without knee pain or disorder of the knee. With regard to knee extension strength and the above three motions, the elderly with a knee disorder are inferior to the elderly with knee pain; moreover, they face difficulties in performing activities related to the knee joints. In addition, knee disorders may cause a decrease in the ability to execute movements using the upper limbs due to a decrease in physical active mass caused by the knee disorder.

\section{REFERENCES}

[1] Hurley, M.V., Rees, J. and Newham, D.J. (1998) Quadriceps function, proprioceptive acuity and functional performance in healthy young, middle-aged and elderly subjects. Age and Ageing, 27, 55-62. http://dx.doi.org/10.1093/ageing/27.1.55

[2] Jochanan, S., Robert, H.R., Aaron, C., Eliana, E.M. and Jeremy, M.J. (2009) Physical activity, function, and longevity among the very old. Archives of Internal Medicine, 169, 1476-1483.

http://dx.doi.org/10.1001/archinternmed.2009.248

[3] Tinetti, M.E. and Williams, C.S. (1998) The effect of falls and fall injuries on functioning in community-dwelling older persons. Journal of Gerontology: Medical Sciences, 53, 112-119. http://dx.doi.org/10.1093/gerona/53A.2.M112

[4] Mary, E. and Tinetti, M.D. (2003) Preventing falls in elderly persons. New England Journal of Medicine, 348, 42-49. http://dx.doi.org/10.1056/NEJMcp020719

[5] Aoki, K. (2008) Relationships among QOL, ADL, physical activity and self-rated health in the elderly living at home. Journal of Social Welfare, 49, 71-84.

[6] Okanishi, T. and Tsurumi, T. (2001) Physiotherapy of leg joint disorders. 1st Edition, Mitsuwa Shoten, Tokyo.

[7] Peat, G., McCarney, R. and Croft, P. (2001) Knee pain and osteoarthritis in older adults: A review of community burden and current use of primary health care. Annals of the Rheumatic Diseases, 60, 91-97.

http://dx.doi.org/10.1136/ard.60.2.91

[8] Tennant, A., Fear, J., Pickering, A., Hillman, M., Cutts, A. and Chamberlain, M.A. (1995) Prevalence of knee problems in the population aged 55 years and over: Identifying the need for arthroplasty. British Medical Journal, 310, 1291-1293. http://dx.doi.org/10.1136/bmj.310.6990.1291

[9] Ikushima, H., Hidaka, M. and Ikeda, K. (1994) The relationship between activities of daily living and pain and/or muscle strength in patients with osteoarthritis of the knee. Physiotherapy, 21, 347-350.

[10] Murray, M.P., Duthie, E.H., Gambert, S.R., Sepic, S.B. and Mollinger, L.A. (1985) Age-related differences in knee muscle strength in normal women. Journal of Ger- 
ontology, 40, 275-280.

http://dx.doi.org/10.1093/geronj/40.3.275

[11] Borges, O. (1989) Isometric and isokinetic knee extension and flexion torque in men and women aged $20-70$. Scandinavian Journal of Rehabilitation Medicine, 21, 4553.

[12] Frontera, W.R., Hughes, V.A., Lutz, K.J. and Evans, W.J. (1991) A cross-sectional study of muscle strength and mass in 45- to 78-yr-old men and women. Journal of Applied Physiology, 71, 644-650.

[13] Kirsten, G.N. (2009) Gait analysis by observation. 1st Edition, Igaku-Shoin, Tokyo.

[14] Hunter, G.R., Treuth, M.S., Weinsier, R.L., Kekes-Szabo, T., Kell, S.H., Roth, D.R. and Nicholson, C. (1995) The effects of strength conditioning on older women's ability to perform daily tasks. Journal of the American Geriatrics Society, 43, 756-760.

[15] Corrigan, D. and Bohannon, R.W. (2001) Relationship between knee extension force and stand-up performance in community-dwelling elderly women. Archives of Physical Medicine and Rehabilitation, 82, 1666-1672. http://dx.doi.org/10.1053/apmr.2001.26811

[16] Oya, Y., Nakamura, M., Tabata, E., Morizono, R., Mori, S., Komuro, Y. and Horikawa, E. (2008) Fall risk assessment and knee extensor muscle activity in elderly people. Journal of Geriatrics, 45, 308-314.

[17] Zaharni, K.S. and Bakheit, A.M. (2002) A study of the gait characteristics of patients with chronic osteoarthritis of the knee. Disability and Rehabilitation, 24, 275-280. http://dx.doi.org/10.1080/09638280110087098

[18] Zoltan, B., Robert, P., Arpad, I., Rita, M.K. (2006) The influence of walking speed on gait parameters in healthy people and in patients with osteoarthritis. Knee Surgery, Sports Traumatology, Arthroscopy, 14, 612-622. http://dx.doi.org/10.1007/s00167-005-0005-6

[19] Mc Alindon, T.E., Snow, S., Cooper, C. and Dieppe, P.A. (1992) Patterns of osteoarthritis of the knee joint in the community: The importance of the patellofemoral joint. Annals of the Rheumatic Diseases, 51, 844-849. http://dx.doi.org/10.1136/ard.51.7.844

[20] Reilly, S.C., Muir, K.R. and Doherty, M. (1996) Screening for pain in knee osteoarthritis: Which question? $A n-$ nals of the Rheumatic Diseases, 55, 931-933. http://dx.doi.org/10.1136/ard.55.12.931

[21] Urwin, M., Symmons, D., Allison, T., Brammah, T., Busby, H. and Roxby, M. (1998) Estimating the burden of musculoskeletal disorders in the community: The comparative prevalence of symptoms at different anatomical sites, and the relation to social deprivation. Annals of the Rheumatic Diseases, 57, 649-655. http://dx.doi.org/10.1136/ard.57.11.649

[22] Sugiura, H. and Demura, S. (2012) Effect of subjective knee joint pain on knee extension strength, gait and ADL score in the female elderly. Gazzetta Medica Italiana, 171, 533-540.

[23] Demura, S., Sato, S., Minami, M., Kobayashi, H., Noda, Y., Matsuzawa, J., Kobayashi, K. and Aoki, J. (2000) Development of ADL index for older community people.
Japanese Journal of Physical Fitness and Sports Medicine, 49, 375-384.

[24] Sato, S., Demura, S., Matsuzawa, J., Noda, Y., Miyaguchi, H., Tada, N., Kobayashi, H., Goshi, F., Minami, M. and Sugano, N. (2000) Development of ADL index for healthy older persons: Proposal of useful ADL items and their scales. Journal of Physical Education Health and Sport Sciences, 45, 472-488.

[25] Oida, Y. and Nakamura, N. (2008) Exercise learning support manual for the knee joint ache prevention and reduction. 1st Edition, Sunlife Plan, Tokyo.

[26] Bellamy, N., Buchanan, W.W., Goldsmith, C.H., Campbell, J. and Stitt, L.W. (1988) Validation study of WOMAC: A health status instrument for measuring clinically important patient relevant outcomes to antirheumatic drug therapy in patients with osteoarthritis of the hip or knee. Journal of Rheumatology, 15, 1833-1840.

[27] Hashimoto, H., Hanyu, T., Sledge, C.B. and Lingard, E.A. (2003) Validation of a Japanese patient-derived outcome scale for assessing total knee arthroplasty: Comparison with Western Ontario and McMaster Universities osteoarthritis index (WOMAC). Journal of Orthopaedic Science, 8, 288-293. http://dx.doi.org/10.1007/s10776-002-0629-0

[28] Astephen, J.L., Deluzio, K.J., Caldwell, G.E. and Dunbar, M.J. (2008) Biomechanical changes at the hip, knee, and ankle joints during gait are associated with knee osteoarthritis severity. Journal of Orthopaedic Research, 26, 332-341. http://dx.doi.org/10.1002/jor.20496

[29] Sugiura, H. and Demura, S. (2012) Effect of subjective knee-joint pain on the laterality of knee extension strength and gait in elderly women. Archives of Gerontology and Geriatrics, 54, 366-369.

http://dx.doi.org/10.1016/j.archger.2011.04.024

[30] Morrison, J.B. (1970) The mechanics of the knee joint in relation to normal walking. Journal of Biomechanics, 3, 51-61. http://dx.doi.org/10.1016/0021-9290(70)90050-3

[31] Oliveria, S.A., Felson, D.T., Cirillo, P.A., Reed, J.I. and Walker, A.M. (1999) Body weight, body mass index, and incident symptomatic osteoarthritis of the hand, hip and knee. Epidemiology, 10, 161-166.

http://dx.doi.org/10.1097/00001648-199903000-00013

[32] Yoshimura, N., Nishioka, S., Kinoshita, H., Hori, N., Nishioka, T., Ryujin, M., Mantani, Y., Miyake, M., David, C. and Cyrus, C. (2004) Risk factors for knee osteoarthritis in Japanese women: Heavy weight, previous joint injuries, and occupational activities. Journal of Rheumatology, 31, 157-162.

[33] Spector, W.D., Katz, S., Murphy, J.B. and Fulton, J.P. (1987) The hierarchical relationship between activities of daily living and instrumental activities of daily living. Journal of Chronic Diseases, 40, 481-489. http://dx.doi.org/10.1016/0021-9681(87)90004-X

[34] Kim, H.S., Matsuura, Y., Tanaka, K. and Inagaki, A. (1993) Facyorial structure and establishment of a test battery to evaluate ability of daily living activity in the elderly. Journal of Physical Education Health and Sport Sciences, 38, 187-200. 